Jurnal Abdimas Berdaya : Jurnal Pembelajaran, Pemberdayaan dan Pengabdian Masyarakat

Volume 4 Nomor 01 Tahun 2021

P-ISSN: $2685-1563$

e-ISSN: 2720 - 9768

\title{
Pembangunan Pintu Air Irigasi Untuk Efisiensi Distribusi Air Bagi Petani Di Daerah Tumpang Kabupaten Malang
}

\section{Title Consists of Two Languages Written in Times New Roman 12pt, 1 Space All Bold and Capitalized at the Beginning of the Word}

\author{
Bambang Suprapto ${ }^{1)}$, Eko Noerhayati ${ }^{2)}$ \\ 1,2 Universitas Islam Malang \\ e-mail: ${ }^{1}$ bambangsup.unisma@gmail.com, ${ }^{2}$ eko.noerhayati@unisma.ac.id
}

\begin{abstract}
Abstrak: Pengabdian pada Daerah Irigasi Tumpang Kabupaten Malang bertujuan untuk meningkatkan kesejahteraan masyarakat desa melalui pemberdayaan dan pembinaan petani. Pemberdayaan dan pembinaan petani untuk meningkatan hasil panen dengan cara efisiensi kebutuhan air irigasi teknis mendampingi pembangunan pintu air pada bangunan bagi saluran tersier. Kegiatan ini dilakukan bekerjasama dengan pemerintah Desa Sukoanyar, kelompok tani dan Dinas Pekerjaan Umum Sumber Daya Air Kabupaten Malang. Kegiatan pengabdian ini melakukan pembangunan pintu air irigasi dengan 3 kelompok tani di desa Sukoanyar yaitu kelompok tani Dewi Ratih I, Dewi ratih II dan Dewi Ratih III. Survei lapangan menemukan masalah pada mitra yaitu terdapat sarana jaringan irigasi tersier telah rusak, belum ada sistem manajemen untuk pola tanam, lembaga pada kelompok tani masih lemah. Solusi yang ditawarkan adalah memperbaiki sistem pembagian air pada saluran tersier. perbaikan tersebut adalah mengadakan sarana jaringan irigasi membuat pintu air pada bagunan bagi saluran tersier. Metode pelaksanaan kegiatan pengabdian adalah Participatory Rural Appraisal (PRA) yang melibatkan masyarakat pada perencanaan, pelaksanaan dan evaluasi program. Hasil yang diperoleh yaitu tersediannya sarana pintu air pada bangunan bagi tersier di desa Sukoanyar Kecamatan Pakis Kabupaten Malang dan distribusi air di sawah menjadi efisien sesuai dengan kebutuhan petani.
\end{abstract}

Kata Kunci: Daerah, Irigasi, Tani, Pintu

Abstract: Dedication to the irrigation area of Malang Regency Overlap aims to improve the welfare of rural communities through the empowerment and development of farmers. Empowerment and development of farmers to increase crop yields in technical efficiency irrigation need accompany the development floodgates for building tertiary canals. This activity is carried out in cooperation with the village government Sukoanyar, farmer groups, and the Department of Public Works Water Resources of Malang. This service activity performed the construction of irrigation locks with three groups of farmers in the village Sukoanyar, namely Dewi Ratih farmer groups I, II, and III Dewi Ratih Dewi Ratih. A field survey that found that there are problems in network infrastructure associated with tertiary irrigation has been damaged; there is a management system for cultivation, the institution remains weak groups of farmers. The solution offered is to improve the water distribution system in the tertiary canals. Developing the irrigation network is organized means making floodgates in buildings for commercial channels. The methods of the activities of the service implementation are participatory rural appraisal (PRA) involving the community in planning, implementation, and evaluation of programs. The results obtained through gates are available for commercial buildings in the village Sukoanyar Pakis subdistrict Malang and distribution of water in the fields to be efficient according to the needs of farmers.

Keywords: Area, Irrigation, Farmer, Door

JURNAL ABDIMAS BERDAYA: Volume 4 Nomor 01 Tahun 2021 


\section{A. Pendahuluan}

Kabupaten Malang memiliki luas wilayah 3.530,65 $\mathrm{km}^{2}$ adalah kabupaten terluas kedua di Jawa Timur setelah Kabupaten Banyuwangi dan merupakan kabupaten dengan populasi terbesar di Jawa Timur. Kabupaten Malang secara geografis terletak pada1 $12^{\circ} 17^{\prime}$ - $112^{\circ} 57^{\prime}$ BT dan $7^{\circ} 44^{\prime}$ - 8 86 $^{\circ}$ LS.Pemerintahan Kabupaten Malang memiliki visi dan misi untuk mewujudkan sistem agribisnis yang mandiri, produktif, efisien dan berdayasaing tinggi untuk menuju pertanian berkelanjutan, dengan memanfaatkan potensi sumberdaya manusia secara optimal. Dalam pelaksanaannya, Kabupaten Malang menitik beratkan potensinya dalam bidang pertanian khususnya sub sektor tanaman pangan. (Noerhayati dan Suprapto 2020)

Desa Sukoanyar adalah salah satu desa di Kecamatan Pakis, Kabupaten Malang. Desa ini memiliki luas wilayah 344.983 ha, berada pada ketinggian $600 \mathrm{~m}$ Dpl dan memiliki curah hujan sebesar $2500 \mathrm{~mm} / \mathrm{th}$. Jumlah penduduk desa ini sebanyak 6.779 jiwa dan terbagi dalam 1.898 kepala keluarga. Dari segi sosial ekonomi, mata pencaharian penduduk desa Sukoanyar, mayoritas adalah petani dan buruh tani (50\%), karyawan swasta (23,5\%), pedagang (10\%) dan lain-lain. Menurut (Dian 2013) perlakuan pengelolaan air berpengaruh terhadap tinggi tanaman dan jumlah anak tanaman serta hasil panen, (Hidayat dan Harlan 2012) Optimalisasi penggunaan air irigasi memerlukan pengelolaan yang terarah dan terencana.

Luas lahan pertanian di Desa Sukoanyar adalah sebesar 246.610 ha, dengan jenis tanaman padi dan palawija. Potensi sumber daya alam terbesar yang dimiliki oleh Desa Sukoanyar dari sektor pertanian adalah jenis tanaman padi yaitu seluas 82.203 ha. Berdasarkan program pemerintah Kabupaten Malang, untuk meningkatkan produktifitas sektor pertanian, maka pemerintahan Desa Sukoanyar membentuk kelompok tani sebagai sarana komunikasi, diskusi dan koordinasi. Kelompok tani yang terdaftar di lembaga pemerintahan desa diantaranya adalah sebagai berikut:

1. Dewi Ratih I

2. Dewi Ratih II

3. Dewi Ratih III

Tiga kelompok tani tersebut adalah kelompok tani dengan target komoditas utama berupa tanaman pangan padi. Tabel 1 menunjukkan luas lahan serta jumlah keanggotaan dari masing-masing kelompok tani.

Tabel 1. Luas lahan dan keanggotaan kelompok tani

\begin{tabular}{|c|l|c|c|c|}
\hline \multirow{2}{*}{ No } & Keterangan & \multicolumn{3}{|c|}{ Kelompok Tani } \\
\cline { 3 - 5 } & & Dewi Ratih I & Dewi Ratih II & Dewi Ratih III \\
\hline 1 & Total luas lahan pertanian (ha) & 67 ha & 45 ha & 142 ha \\
\hline 2 & Jumlah anggota (orang) & 115 & 60 & 200 \\
\hline 3 & Jumlah anggota aktif (orang) & 15 & - & 35 \\
\hline
\end{tabular}

Hasil survey kondisi aktual di lapangan (Gambar 1) menunjukkan bahwa untuk membangun dan mengembangkan Desa Sukoanyar menjadi desa bina tani mandiri, memiliki beberapa faktor pendukung antara lain: (1) Potensi pasar yang luas, karena 
padi merupakan kebutuhan pokok masyarakat Indonesia, (2) Kondisi lahan yang subur sebagai modal dasar produktifitas pertanian, (3) Akses pemasaran yang mudah (4 km ke ibukota kecamatan, $37 \mathrm{~km}$ ke ibukota kabupaten dan $16 \mathrm{~km}$ ke pusat kota Malang), (4) Bibit padi diperoleh dari dinas pertanian dan (5) Ketersediaan embung sebagai sumber irigasi di desa tersebut.

Disisi lain terdapat beberapa masalah yang ditemui dalam pelaksanaan budidaya pertanian di Desa Sukoanyar yang berkaitan dengan pelaksanaan teknis. Permasalahan ini dapat diidentifikasi dari masing-masing kelompok tani yang terbentuk, baik itu masalah operasional ataupun masalah kelembagaan sebagai berikut:

1. Kelompok Tani Dewi Ratih I

Kelompok tani Dewi Ratih I mengalami beberapa masalah sebagai berikut:

a. Harga padi hasil panen tidak seragam, tidak stabil dan jauh dari harga normal dipasaran. Proses pemasaran tidak dilakukan secara terkoordinir, sehingga seringkali petani harus memasarkan sendiri hasil panennya. Harga jual hasil panen juga fluktuatif mengikuti harga pasar,akan tetapi harganya jauh lebih rendah dari harga normal di pasaran dengan perbedaan harga sampai $20 \%$.

b. Debit irigasi yang sering tidak sesuai dengan kebutuhan.

Jenis tanaman sangat menentukan jumlah air irigasi yang dibutuhkan, sebagai contoh untuk tanaman padi maka kebutuhan air irigasi akan lebih besar jika dibanding dengan palawija. Masalah tersebut sering kali terjadi karena tidak adanya koordinasi antar sesama petani serta tidak adanya koordinasi dengan pihak pengairan. Jika supply air tidak sesuai dengan kebutuhan tanaman, maka akan berakibat turunnya kualitas hasil panen bahkan terjadi kegagalan panen.

c. Serangan hama pada musim tertentu.

Pada musim penghujan, curah hujan akan meningkat sehingga kebutuhan air irigasi akan terpenuhi. Pada kondisi tersebut jenis tanaman padi akan memperoleh hasil yang maksimal akan tetapi pada musim penghujan seringkali serangan hama meningkat dan menjadi suatu sebab petani tidak menanam padi dengan maksimal.

2. Kelompok Tani Dewi Ratih II

Beberapa masalah yang dihadapi oleh kelompok tani Dewi Ratih II adalah sebagai berikut:

a. Harga padi saat panen yang cenderung rendah dan tidak stabil.

Karena harga jual hasil panen yang seringkali tidak stabil, maka petani dari kelompok Dewi Ratih II, lebih sering menjual dalam sistem borongan (tebas). Penjualan sistem tebas ini seringkali menjadi masalah karena harganya memang selalu jauh dibawah harga pasar.

b. Tidak adanya pintu air pada saluran irigasi tertier dan quarter.

Sistem irigasi mengalirkan air dari embung menuju ke lahan persawahan melalui saluran irigasi. Jenis saluran irigasi ini dibagi dalam empat jenis, yaitu: primer, sekunder, tersier dan kwarter Anonim. (2013). Tanggung jawab operasional dan 
perawatan dari saluran irigasi ini telah disepakati antar pihak UPT SDA dan Irigasi dengan himpunan petani, dimana saluran primer dan sekunder dibawah tanggung jawab UPT SDA dan Irigasi, sedangkan petani bertanggung jawab terhadap saluran tersier dan kwarter. Dalam pelaksanaannya, tanggung jawab operasional pada saluran tersier dan kwarter tidak berjalaan dengan baik karena tidak adanya pintu air yang merupakan sarana irigasi yang vital, sehingga debit air yg masuk tidak bisa terkontrol dan kurang efisien

c. Debit air irigasi yang tidak stabil

Debit air irigasi yang tidak stabil ini dialami oleh kelompok tani Dewi Ratih II. Penyebab utama dari masalah ini adalah adanya sedimentasi di beberapa titik pada saluran irigasi kwarter.

3. Kelompok Tani Dewi Ratih III

a. Kurangnya debit air irigasi pada musim tanam tertentu (musim kemarau)

Dalam 1 tahun, sesuai dengan masa tanam padi yaitu 4 bulan panen, maka petani melakukan 3 Musim Tanam (MT) yang disesuaikan dengan kondisi curah hujan yang berhubungan dengan ketersediaan air untuk irigasi. Musim Tanam (MT) ini terdiri dari:

(1) Musim Hujan (MH), (2) Musim Kemarau 1 (MK 1) atau Musim Gadu, dan

(3) Musim Kemarau 2 (MK 2).

b. Tidak adanya pintu air pada saluran irigasi tersier dan kwarter

c. Pemasaran hasil panen yang sulit, sehingga seringkali harus dijual ke pihak tengkulak.

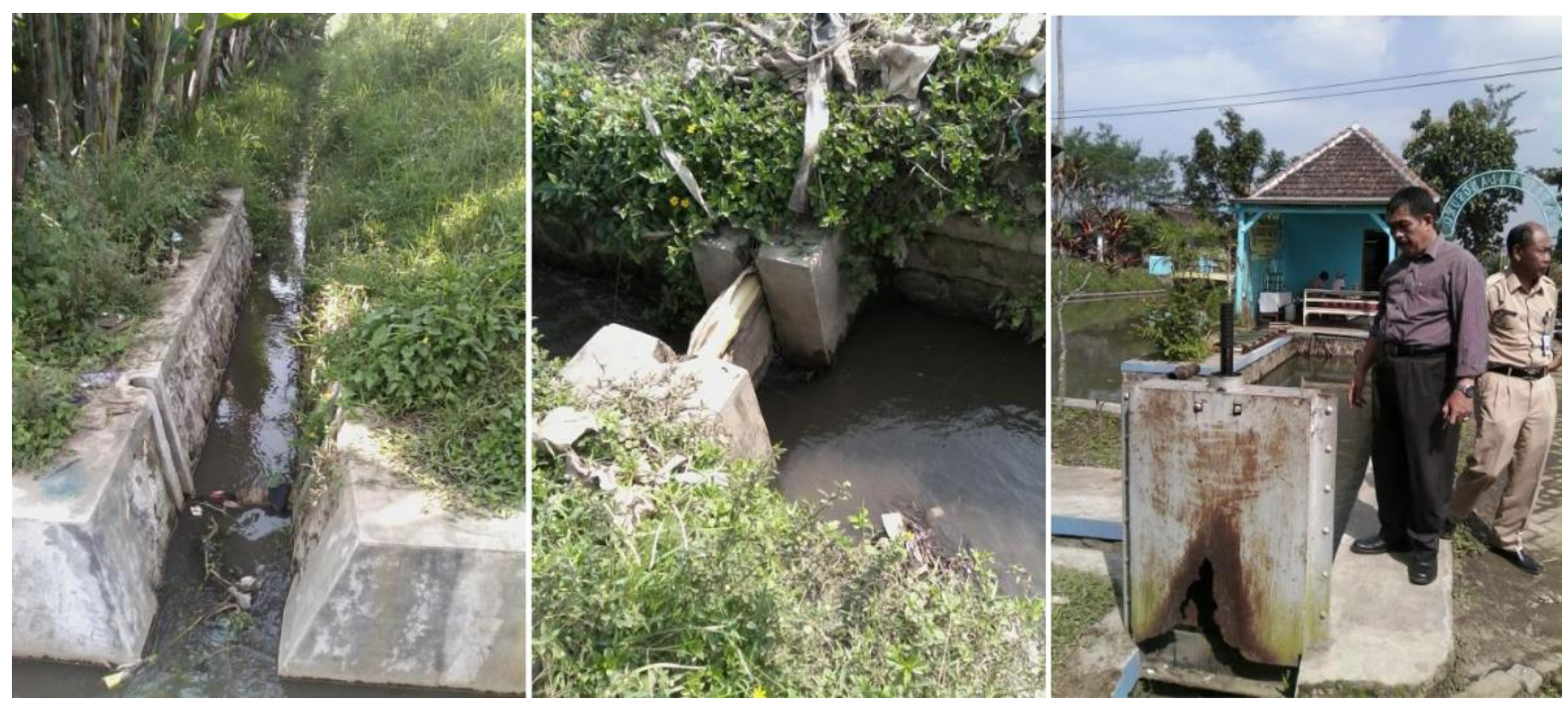

Gambar 1. Kondisi pintu air di saluran sekunder dan tersier

Selain masalah tersebut, dari hasil diskusi awal dengan pihak pemerintahan desa dan UPT SDA dan Irigasi, didapatkan beberapa masalah terjadi pada kelompok tani tersebut, diantaranya: 
a. Produktifitas hasil panen padi yang belum memenuhi target

Dalam 1 tahun, sesuai dengan masa tanam padi yaitu 4 bulan panen, maka petani melakukan 3 Musim Tanam (MT) yang disesuaikan dengan kondisi curah hujan yang berhubungan dengan ketersediaan air untuk irigasi. Musim Tanam (MT) ini terdiri dari:

(1) Musim Hujan (MH), (2) Musim Kemarau 1 (MK 1) atau Musim Gadu, dan

(3) Musim Kemarau 2 (MK 2). Pada masing-masing MT petani akan menanam padi dan palawija dengan komposisi berbeda setiap MT menyesuaikan dengan kondisi air irigasi. MT ini biasa juga disebut dengan IP (indeks Pertanaman).Dalam satu tahun jika mengalami 3 kali masa panen maka IP maksimum adalah 300.Dari kondisi IP maksimum 300, dengan perhitungan pola tanam padi - palawija, pemerintahan Desa Sukoanyar menetapkan target IP padi sebesar 190, sedangkan aktual nya hanya tercapai maksimum 160. Tabel 2 berikut akan menggambarkan perbandingan komposisi pola tanam aktual jika dibandingkan dengan target pemerintah Desa Sukoanyar.

Tabel 2. Perbandingan komposisi pola tanam target dan aktual

\begin{tabular}{|l|l|c|c|c|c|}
\hline \multirow{2}{*}{ No } & \multicolumn{2}{|c|}{ Musim Tanam } & \multicolumn{2}{|c|}{ Target } & \multicolumn{2}{c|}{ Aktual } \\
\cline { 3 - 6 } & & Padi (\%) & Palawija (\%) & Padi (\%) & Palawija (\%) \\
\hline 1 & Musim Hujan (MH) & 90 & 10 & 60 & 40 \\
\hline 2 & Musim Kemarau 1 (MK 1) & 60 & 40 & 60 & 40 \\
\hline 3 & Musim Kemarau 2 (MK 2) & 40 & 60 & 40 & 60 \\
\hline \multicolumn{2}{|l}{ TOTAL IP PADI } & 190 & & 160 & \\
\hline
\end{tabular}

Selain penetapan target pola tanam, pemerintah desa juga mentargetkan hasil panen padi sebesar 9 ton/ha, akan tetapi hasil panen rata-rata yang dicapai oleh petani Desa Sukoanyar adalah sebesar 7,5 ton/ha.

b. Komunikasi dan koordinasi antara petani dengan pihak irigasi yang kurang lancar.

Untuk kebutuhan sarana irigasi, Desa Sukoanyar berada di wilayah UPT SDA (Unit Pelaksana Teknis Sumber Daya Air) dan Irigasi Tumpang. UPT SDA dan Irigasi Tumpang ini menaungi 2 kecamatan, yaitu Kecamatan Pakis dan Kecamatan Tumpang. Sistem Irigasi adalah syarat vital dalam sektor pertanian, masalah utama dalam sistem irigasi adalah ketersediaan air yang tidak tak terbatas, sehingga penggunaan air secara efisien merupakan hal yang penting tanpa mengurangi produktifitas hasil panen.Keterbatasan air untuk irigasi inilah yang menjadikan UPT SDA dan Irigasi berkewajiban mengatur debit air untuk irigasi setiap tahunnya, ketersediaan air yang melimpah pada musim penghujan dan minimnya air pada musim kemarau harus bisa diperhitungkan agar kegiatan pertanian tetap bisa berjalan secara produktif sepanjang tahun.Untuk menjaga produktifitas pertanian diperlukan koordinasi dan komunikasi antara petani 
dengan pihak irigasi,(Maarif, Noerhayati, dan Rachmawati 2019) hal ini untuk mensingkronkan pola tanam petani dengan kondisi air irigasi yang tersedia sehingga tidak terjadi gagal panen akibat kurangnya supply air. Pada pelaksanaannya komunikasi dan koordinasi petani dengan pihak irigasi berjalan kurang lancar.

c. Fungsi kelembagaan pada kelompok tani masih lemah.

Dibentuknya kelompok tani oleh pemerintahan desa bertujuan untuk menunjang program pemerintah desa dalam meningkatkan produktifitas hasil pertanian dan tujuan akhir untuk meningkatkan kesejahteraan penduduk Desa Sukoanyar.Dalam kelompok tani ini memiliki kegiatan rutin berupa pertemuan bulanan dan pembersihan saluran irigasi rutin setiap tahunnya. Dengan adanya kegiatan rutin ini diharapkan akan membawa dampak positif yang menunjang produktifitas pertanian, akan tetapi pada pelaksanaannya fungsi kelembagaan pada kelompok tani ini masih lemah dan bahkan tidak berjalan terutama untuk kelompok tani Dewi Ratih II.

Berdasarkan potensi daerah, arah kebijakan pembangunan pemerintah Kabupaten dan desa, serta kesediaan masyarakat, maka Desa Sukoanyar layak dipilih menjadi desa bina tani mandiri di Kabupaten Malang. Kegiatan Program Pengabdian pada masyarakat ini akan dilaksanakan secara bersinergi antara Universitas Islam Malang, pemerintah Kabupaten yang diwakili oleh Dinas PU Sumber Daya Air Tumpang serta masyarakat petani Desa Sukoanyar.

Berdasarkan hasil diskusi dengan kelompok tani mitra, maka permasalahan prioritas yang akan ditangani adalah sebagai berikut:

1. Kurangnya beberapa sarana vital pada jaringan irigasi tersier

Dari ketiga kelompok tani, permasalahan umum yang dihadapi adalah kurangnya sarana vital pada jaringan irigasi tersier, terutama berupa bangunan pintu air. Ketersediaan sarana yang berupa bangunan pintu air ini sangat berpengaruh pada pengaturan penggunaan air irigasi yang nantinya akan mempengaruhi ketersediaan air sepanjang musim tanam serta keteraturan pola tanam dari petani. Dengan adanya pengontrolan debit air irigasi, maka pola tanam sepanjang musim akanlebih teratur dan produktifitas pertanian akan terjaga.

2. Terbatasnya pengetahuan dan teknologi pada kelompok tani

Beberapa teknologi dalam budidaya pertanian sudah diketahui oleh beberapa anggota kelompok tani, tetapi masih belum memahami cara pemberian air sesuai dengan pola tanamnya. Pola tanam yang terjadi pada saat ini kurang efektif sehingga hasil panen yang didapat kurang maksimal. Contoh permasalahan lain, tidak stabilnya debit air irigasi yang dialami oleh kelompok tani Dewi Ratih II, ternyata dikarenakan sedimentasi pada saluran irigasi dan pembagian air di bagunan bagi tersier, sehingga diperlukan penyuluhan dan pelatihan sistem maintenance dan operasi saluran irigasi. Belum adanya sistem manajemen produksi dan keuangan sederhana yang diterapkan 
oleh anggota kelompok tani. Sebagai contoh, tidak adanya pembukuan tentang proses produksi dan budidaya pertanian baik itu berupa catatan hasil produksi, pemasaran, pemasukan serta pengeluaran keuangan.

\section{B. Metode}

\section{Metode Pendekatan Kegiatan}

Untuk mencapai tujuannya, kegiatan PPDM Bina Tani Mandiri Desa Sukoanyar akan dilakukan melalui beberapa pendekatan, antara lain:

1. Model Participatory Rural Appraisal (PRA) yang menekankan keterlibatan masyarakat dalam keseluruhan kegiatan mulai dari perencanaan, pelaksanaan dan evaluasi program kegiatan.(Balgah 2016)

2. Model Participatory Tecnology Development yang memanfaatkan teknologi tepat guna yang berbasis pada ilmu pengetahuan dan kearifan budaya lokal.(Arevian dkk. 2018)

3. Model Community development yaitu pendekatan yang melibatkan masyarakat secara langsung sebagai subyek dan obyek pelaksanaan kegiatan pengabdian kepada masyarakat.(Rubin, Rubin, dan Doig 1992)

4. Persuasif yaitu pendekatan yang bersifat himbauan dan dukungan tanpa unsur paksaan bagi masyarakat untuk berperan aktif dalam kegiatan ini.(Indrihastuti, Murtilaksono, dan Tjahjono 2016)Edukatif yaitu pendekatan sosialisasi, pelatihan dan pendampingan sebagai sarana transfer ilmu pengetahuan dan pendidikan untuk pemberdayaan masyarakat.

\section{Teknis Pelaksanaan Kegiatan}

Secara teknis, pelaksanaan kegiatan PPM Desa Sukoanyar adalah sebagai berikut:

1. Persiapan.

Kegiatan ini dilakukan untuk menginventarisasi kondisi masyarakat khususnya kelompok tani sehingga desain kegiatan yang akan dilakukan dapat memberikan solusi bagi permasalahan mitra. Selain itu di tahap awal ini juga akan dilakukan sosialisasi program disertai survei pemilihan lokasi saluran yang akan dibangun pintu air.

2. Pelaksanaan kegiatan.

Pelaksanaan kegiatan meliputi kegiatan pendampingan pembuatan dan pemasangan fasilitas sarana pintu air pada saluran tersier melalui kelompok tani dan Himpunan petani pemakai Air (HIPA,) kegiatan peningkatan SDM kelompok tani dengan memberikan pendampingan operasi dan pemeliharaan pintu air pada saluran sehingga petani dapat mengelola pintu air irigasi dengan baik.

3. Evaluasi dan monitoring kegiatan.

Evaluasi dan monitoring kegiatan pembangunan dilakukan secara periodic selama pembangunan dengan melibatkan anggota pelaksana/tim pembangunan 


\section{Hasil dan Pembahasan \\ Pintu Sorong untuk Saluran}

Pintu yang dipasang pada saluran tersier ini telah direncanakan untuk eksploitasi dengan mur ganda agar terhindar dari kemungkinan macet dalam sponing, yang bentangnya sekitar 1,50 kali tingginya.(Wibisono, Sayekti, dan Wicaksono 2016) Terdapat batasan pada bentuk pintu tipe setang tunggal. Hal ini berkaitan dengan kelonggaran jalan samping untuk gerak yang diizinkan dalam penuntun pintu, apabila pintu diturunkan berubah-ubahnya koefisien geser tidak dapat dihindarkan pada tiap sisi pintu yang dapat memiringkan daun pintu dan kemungkinan sebagai penyebab macet dalam penuntunnya, ini berarti bahwa (dengan anggapan kelonggaran kerja standar pada tiap sisi pintu) pintu dengan daun pintu dangkal dapat miring dalam penuntunnya lebih dari pada pintu dengan daun pintu dalam (tinggi). Jadi pintu dengan setang penggerak tunggal lebih cenderung dipilih bentuk persegi, atau lebih besar tingginya dari pada bentang. Suatu batasan mutlak pada perbandingan bentang/tinggi sekitar 2/1 umumnya dapat diterima tetapi sejauh mungkin dihindarkan. Lewat batas ini lebih disenangi mempergunakan setang penggerak ganda yang memberikan gaya angkat yang sinkron pada tiap sisi pintu.

Konstruksi engsel, untuk mengaitkan daun pintu ke setang penggerak, yang sesuai dengan standarisasi lebih mahal dalam hal biaya bahan dan tenaga kerja, dari pada kaitan dengan penempaan ujung yang telah banyak digunakan di Indonesia. Bentuk dengan tempaan ujung memberikan ketebalan yang tipis sehingga tidak mempunyai kekakuan sehingga tidak dapat dipertimbangkan sebagai kaitan yang baik. (Irianto 2016) Kaitan engsel dinilai sebagai konstruksi yang hanya memungkinkan derajad gerak lateral terbatas pada kaitan sehingga lebih baik dari pada konstruksi dengan ujung tempaan. Pemasangan pintu akan mengikuti prosedur yang ditentukan dalam Petunjuk Pemasangan, Operasi dan Pemeliharaan" yang disiapkan oleh UPT Sumber Daya Air. Kelompok Tani dan HIPA harus bertanggung jawab menyediakan tenaga kerja, alat-alat pengangkat yang memungkinkan pintu dapat dibawa ketempat bahkan semua alat dan bahan yang memungkinkan pintu dibangun. Tukang pembuat pintu harus bertanggung jawab menyediakan perlengkapan dan alat khusus untuk pemasangan pintu dan pengawasan tenaga kerja.

Pintu harus diangkut kelapangan oleh pembuat pintu. Pintu telah dirakit dahulu di bengkel pembuat pintu sampai siap agar dapat langsung dipasang pada bangunan. Untuk menjamin bahwa bagian rangka benar-benar saling tegak lurus maka dalam prarakit dan perakitan penuh dilapangan, dipergunakan penguat dan penopang sementara. Penopang-penopang sementara ini dibautkan pada bagian rangka dengan baut yang dapat dilepas, untuk memegang rangka pada siku yang benar selama seluruh pekerjaan pemasangan berlangsung. Apabila pemasangan telah selesai penopang sementara dilepas. Pintu dipasang dalam coakan yang sudah disiapkan pada bangunan mempergunakan alat pengangkat yang disediakan. Pintu harus terlindung secara baik dari kerusakan akibat pemindahan. Dipergunakan pemegang sementara dari kayu untuk 
menjamin kerataan ambang bawah dan baji kayu untuk menjamin ketegakan dan kekuatan sementara selama pemasangan pintu. Pintu harus dikontrol dengan untingunting dan penyipat datar untuk penempatan dalam coakan bangunan. Pintu harus dioperasikan dalam siklus penuh dari keadaan tertutup rapat ke terbuka penuh ke tertutup rapat.

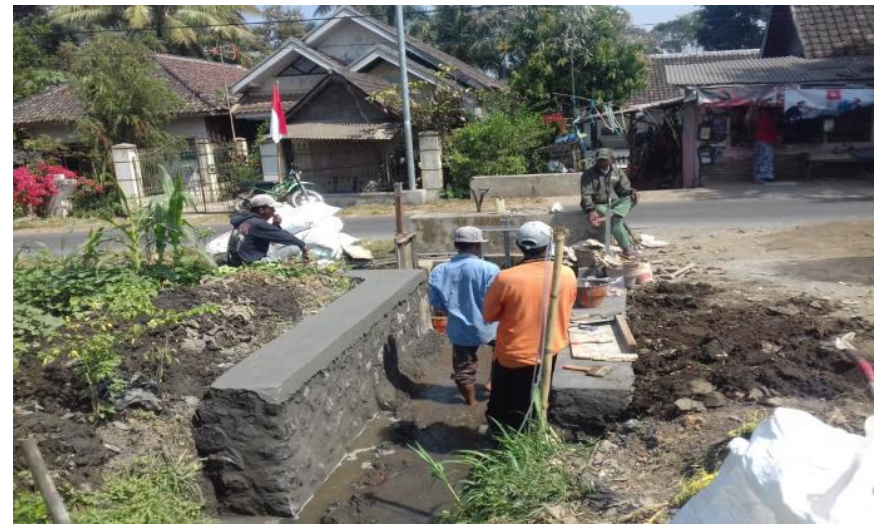

Gambar 2. Kondisi pelaksanaan pembuatan pintu air di saluran tersier

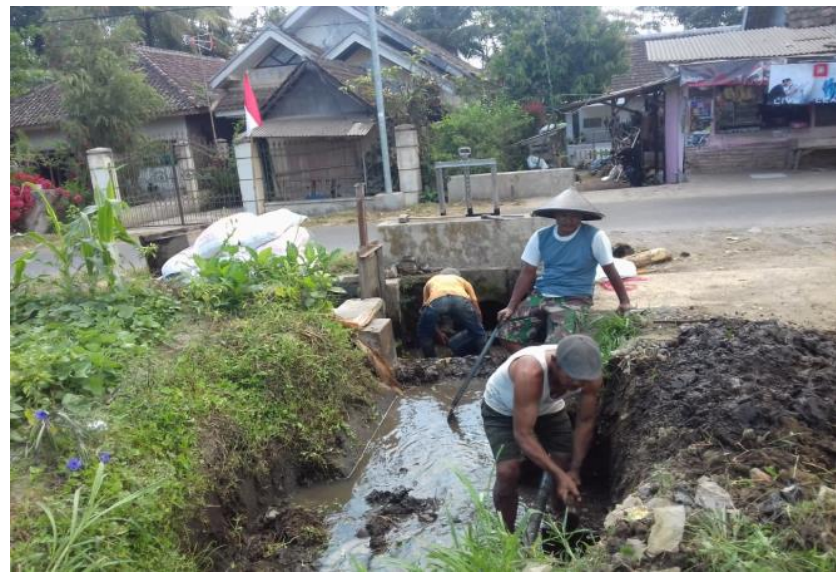

Gambar 3. Kondisi pelaksanaan pembuatan pintu air di saluran tersier

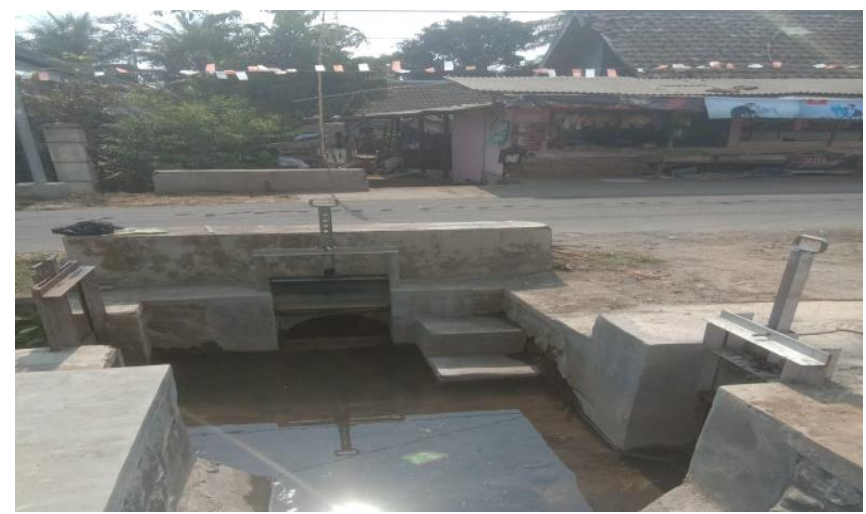

Gambar 4. Kondisi pintu air di saluran tersier yang sudah terpasang 


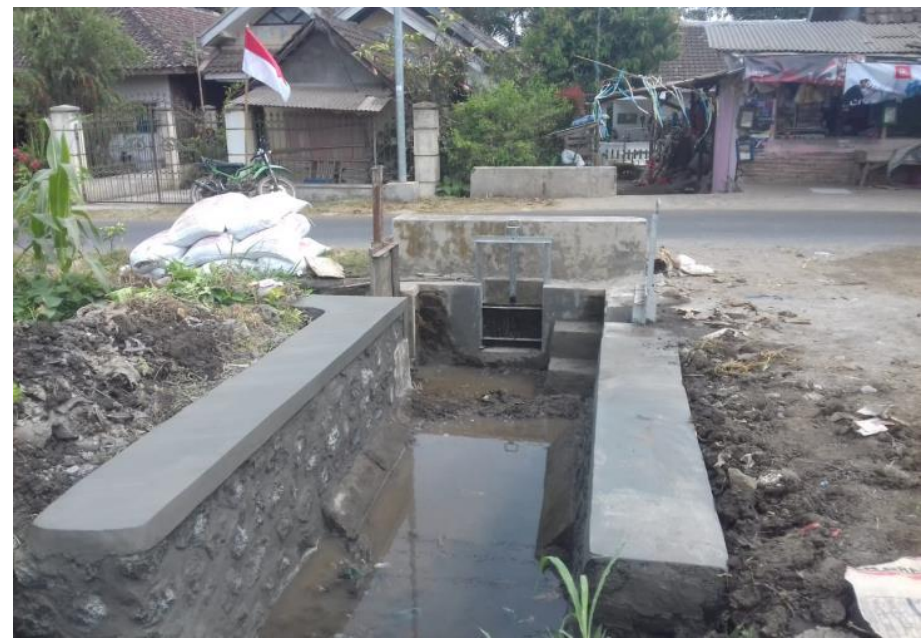

Gambar 5. Kondisi pintu air di saluran tersier yang telah terpasang

\section{Simpulan}

Kegiatan pengabdian dilakukan melalui Participatory Rural Appraisal (PRA) yang melibatkan masyarakat pada perencanaan, pelaksanaan dan evaluasi program. Hasil yang diperoleh yaitu tersediannya sarana pintu air pada bangunan bagi tersier di desa Sukoanyar Kecamatan Pakis Kabupaten Malang sehingga distribusi air di sawah menjadi efisien sesuai dengan kebutuhan petani.

\section{Ucapan Terima Kasih}

Ucapan terimakasih disampaikan kepada Universitas Islam Malang yang telah mendukung pelaksanaan pengabdian melalui hibah HI-ma dan juga pihak yang terlibat dalam program pengabdian di Desa Sukoanyar. 


\section{Daftar Rujukan}

Arevian, Armen C., Jennifer O'Hora, Felica Jones, Joseph Mango, Loretta Jones, Pluscedia G. Williams, Juanita Booker-Vaughns, Andrea Jones, Esmeralda Pulido, dan Denishia Banner-Jackson. 2018. "Participatory technology development to enhance community resilience." Ethnicity \& disease 28 (Suppl 2): 493.

Balgah, Roland Azibo. 2016. "Applying participatory rural appraisal to unlock gender group differences in some communities in rural Cameroon." Asian Journal of Agricultural Extension, Economics \& Sociology, 1-11.

Dian, N. 2013. "Pengaruh Sistem Pengairan Terhadap Pertumbuhan dan Produktivitas Beberapa Varietas Padi Sawah (Oryza sativa L.)." Skripsi Fakultas Pertanian Institut Pertanian Bogor.

Hidayat, Yuliya Mahdalena, dan Dhemi Harlan. 2012. "Kajian Optimalisasi Penggunaan Air Irigasi Di Daerah Irigasi Wanir Kabupaten Bandung." Program Studi Magister Pengelolaan Sumber Daya Air, Fakultas Teknik Sipil dan Lingkungan, Institut Teknologi Bandung.

Indrihastuti, Dinik, Kukuh Murtilaksono, dan Boedi Tjahjono. 2016. "Analisis lahan kritis dan arahan rehabilitasi lahan dalam pengembangan wilayah Kabupaten Kendal Jawa Tengah." TATALOKA 18 (3): 141-56.

Irianto, Irianto. 2016. "Perencanaan Saluran Irigasi Primer di Desa Maroko Kabupaten Yahukimo Provinsi Papua." Jurnal Ilmiah Teknik dan Informatika 1 (1): 13-17.

Maarif, Samsul, Eko Noerhayati, dan Azizah Rachmawati. 2019. "Studi Alternatif Perencanaan Jaringan Irigasi Curah (Sprinkler Irigation) Berbasis Gravitasi Di Desa Poncokusumo." Jurnal Rekayasa Sipil 7 (1): 43-52.

Noerhayati, Eko, dan Bambang Suprapto. 2020. "REHABILITASI SALURAN TERSIER DESA SUKOANYAR PAKIS KABUPATEN MALANG.” Jurnal Abdi Masyarakat 3 (2).

Rubin, Herbert J., Irene Rubin, dan Ron Doig. 1992. Community organizing and development. Macmillan New York.

Wibisono, Andrew Agung, Rini Wahyu Sayekti, dan Prima Hadi Wicaksono. 2016. "Studi Perencanaan Teknis Irigasi Tambak di Desa Pucang Anom Kabupaten Sidoarjo." Diakses melalui http://pengairan. ub. ac. id/pada tanggal 3. 